\title{
Information and Communication Technology (ICT) as Resource for Teaching Surface Area of Solid Shapes in Mathematics in Bayelsa State of Nigeria.
}

\author{
Ado, Isaac Bennet ${ }^{1}$, Abasi, Andrew $\mathrm{Umo}^{2}$, Nwankwo, Florence M (P.hD) ${ }^{3}$ \\ ${ }^{1}$ Science Education Department, University of Uyo, Uyo. \\ ${ }^{2}$ Department of Science Education, Akwa Ibom State University, Mkpat Enin. \\ ${ }^{3}$ Department of Early Childhood, University of Uyo, Uyo.
}

\begin{abstract}
This study investigated information and communication technology as resource for teaching surface area of solid shapes in mathematics in Bayelsa State of Nigeria. The study was guided by three research questions and three hypotheses. The pretest-posttest control group design was adopted for the study. A sample of 105 student teachers constituted the study. Two instruments Mathematics Performance Test (MPT) and Interest Inventory Scale (IIS) were used to collect data on the attitude on the attitude of students' performance and interest respectively. The data collected were analysed using mean and standard deviation, analysis of covariance (ANCOVA) using pretest as covariate. The result indicated that students in the experimental group performance significantly better than those in the control group. The result also indicated that the interest of students in the experimental group was significantly better than those in the control group. There was no significant difference in gender performance. Among others, it was recommended that Mathematics teachers should be encouraged to use ICT as a resource for teaching surface area of solid shape so as to enhance students' interests and performances.
\end{abstract}

Keywords: Information, communication, technology, students' performance, solid shapes, surface area, interest and gender.

\section{Introduction}

The study of mathematics is a basic preparation for information and a gateway into numerous career choices (Okereke, 2006). Mathematics as a school subject is at the base of all the scientific and environmental professions (Ifamujiwa, 2007). According to Ifamujiwa (2007), the knowledge of mathematics equips the child with necessary skills needed for solving related mathematical problems in his daily life. The knowledge promotes the acquisition of accuracy, logical, systematic and orderly arrangement of facts in the individual learner. This is why the Nigerian National Policy on Education has made the subject compulsory at the lower, middle and upper basic including the senior secondary school. It is however unfortunate that over the years, despite the importance of the subject, the performances of students writing mathematics in external examinations conducted by the West African Examination Council (WAEC) has been declining with their grades remaining consistently poor (Folayam and Ibrahim, 2000).

The decline and consistent poor performance of students in mathematics may be due to the poor teaching of teachers (Udousoro, 2006). According to Udousoro (2006), the poor teaching of teachers leave the impression that mathematics is merely a tool subject composed of series of signs, symbols and laws of operations. This situation has led to the majority of students perceive mathematics as difficult, abstract, unattractive, boring, not captivating and not related to daily activities thereby resulting to lack of interest in the subject. Interest in a subject is an important determinant for successfully learning. it is a behavioural characteristics of students that exert significant effect in learning situation in a stable manner thereby enhancing performance. Interest in learning according to Ting (2010), is of two types. They are situational interest and personal interest. Situational interest can be subdivided into cognitive and emotional. According to Ting (2010), emotional interest occurs when the instruction evokes a strong affective respond and cognitive interest occurs when students become engage in the content which is important to the topics under investigation. Ting (2010) citing Pugh \& Bergin (2006) stated that personal interest refers to a situation of a relatively enduring inclination towards a particular activity or content and a disposition that develop in a person with time. The transiting of an individual from emotional to cognitive and from cognitive to personal interest would arose enduring interest in the subject or activity thereby enhance performance in the subject or activity (Ting, 2010). The need today therefore is how the learners can be aroused so that they would be able to learn new knowledge by themselves. Resources are very important materials that can be used to enhance the interest of the students in the learning process.

The non-utilization of available resources by teachers has been shown to be true and also to cause reduced performance and interest in mathematics (Umeh, 2006). Resources are very vital tools in education. 
They aid teaching and learning and includes everything that provides information to the teacher as well as the learner. The teaching and learning of mathematics requires the intensive application of resources that would appeal to all the sense of perception to improve the effectiveness of instruction as well as learning. Akinsola (2000) stated that science teaching and learning can only be meaningful and effective if backed up by the necessary resources to enrich instruction. This is the reason why selecting resources, for a particular concept for classroom delivery is an important routine that a resourceful teacher should undertake while preparing his lesson (Adedibu \& Olayiwola, 2006). Adedibu and Olayiwola further stated that a comprehensive knowledge of the subject matter to be taught and the teachers' thorough understanding of the learning process are vital keys to effective selection and application of the resource during classroom teaching of any subject.

\section{Literature Review}

Information and Communication Technologies (ICT), according to Okigbo \& Okeke (2011) have become within a very short time, one of the basic resource in terms of the building blocks of modern society. He further stated that many countries now regard understanding ICT and mastering the basic skills and concepts of ICT as part of the essence of education, together with reading writing and numeracy.Technology today has a great role to play in the teaching and learning process. Its role is rapidly becoming one of the most important and widely discussed issues in contemporary education policy. According to Ochoyi \& Ukwumonu (2008), the fields of education are of the opinion that technology especially ICT holds a great promise to improve teaching and learning in addition to shaping workforce opportunities. The use of new technological devices as Computer Assisted Instruction (CAI), Computer Based Instruction (CBI), Computer Based Learning (CBL) for curriculum delivery have been found to be very effective in science, technology and mathematics curriculum delivery and also useful to learners in solving of learning tasks in education (Okereke, 2004). ICT is a technology that has tremendously enriched education with new patterns of communication information and instructional delivery.

ICT improves the way mathematics should be taught and enhances students understanding of basic concepts (Ochoyi \& Ukwumonu, 2008). Ochoyi \& Ukwumonu (2008) further stated that the ICT supports the constructivist pedagogy in which students use technology to explore and reach an understanding of mathematical concepts. This according to them promotes higher order thinking and better problem solving strategies. No matter, according to Umeh (2006), the impact and effectiveness of ICT in education had been positive, negative or skeptical from findings. The necessity abounds to use this new technology in mathematics for teaching of surface area of solids in measuration.

Measuration is a concept in mathematics which has to do with measuring state of matters to ascertain the amount or size or weight or quantity of it in a place or over time. It has to do with distance (length), weight (mass) time, temperature, area, etc (Usman \& Eze, 2007). It attempts to answer questions such as "how long"? "How many"? How much surface"? how much space"? (Ochoyi \& Danlodi, 2009).Measuration in the Universal Basic Education (UBE) in Nigeria curriculum reveals that it spans through Basic $1-9$, that is, it is taught all through the classes in the UBE. However, the researcher's interest is on Basic 8, order wise known as Junior Secondary two (JS 2) because that is the class in which surface area of solid shapes is taught. The basic requirement for students in Basic 8 or JSS 2 in the curriculum is to develop interest in representing distances by scale drawing, solve problems on quantitative aptitudes related to planes, shapes, figures and relate the importance of finding the surface area of any of these given shape or figure to real life situations. It requires students to abstract the formular for area through activities, use the formular to the number of faces identified for each shape or figure. This result to the essence of the researcher applying ICT as a resource to enable the students have activities that would lead them to abstract the various faces of a shape, use the formula for calculating difference areas of the faces and also identify the number and type of faces on each figure.

\section{Statement of the Problem}

The lack of understanding of geometry and measuration concepts has caused discouragement leading to lack of interest and poor performance among upper basic students. This has given concern to both mathematicians and mathematics educators because no mathematics teacher in Nigeria can assert that all is well in the teaching of the subject. The computer assisted instruction benefit in the world today cannot be emphasized especially in the contemporary world. There are lots of findings on the instructional value of computer, particularly in advanced countries. There are now several software packages on different subjects used in the computer for lessons which enhances interest and performance of students. The trend today in the world is use of computer resource to enhance teaching and learning. The question therefore arises: Will the use of computer as a resource tool for teaching surface area of solids in mathematics enhance students' performance and interest in the subject? 


\subsection{Purpose of the Study}

This study is aimed at determining the effect of ICT as resource on students' mathematics performance and interest in surface area of solids. Specifically, it is to:

1. Determine the performance of students taught using ICT as resource and those taught without

2. Assess the interest of students taught using ICT as resource and those taught without

3. Compare the performance of male and female students taught using ICT as resource and those taught without.

\subsection{Research Question}

In pursuance of the purpose, the study sought to provide answers to the following research questions:

1. What is the difference between the performance of students taught using ICT as a resource and those taught without

2. What is the difference between the interest of students taught using ICT as a resource and those taught without ICT

3. What difference exist between the performance of male and female students taught using ICT as a resource and those taught without ICT

\subsection{Hypotheses Testing}

The study tested the following hypotheses.

Ho1:There is no significant difference between the performance of students taught using ICT as a resource and those taught without.

Ho2:There is no significant difference between the interest of students taught using ICT as a resource and those taught without.

Ho3:There is no significant difference between the performance of male and female students taught using ICT as a resource and those taught without.

\subsection{Method of Research}

This study adopted the pretest-posttest control group design. This design was adopted because the researchers intended on making comparison between the experimental and control groups in other to draw conclusion on the effectiveness of the teaching method used for the study. The researchers also use the design because of the intents of administering a pretest to ascertain the equivalent level of the students in terms of their performance before giving the posttest after treatment.The study was conducted in Yenagoa Local Government Area (LGA) of Bayelsa State. The population consisted of 2125 students from all the schools in Yenagoa LGA. The purposive sampling technique was used in selecting the two schools. This sampling technique was used because the research was interest in using a school that has a computer laboratory with at least forty five counter systems. The sample selected consisted of 105 students in basic 8 from two schools. The experimental school consisted of 48 students while the control group consisted of 57 students. This study was conducted in 2011/2012 academic session.

Two instruments developed by the researcher were used for the study. Mathematics Performance Test (MPT) and Interest Inventory Scale (IIS). MPT, initially was a 36 multiple choice item questions of four options each having the correct answer among them. All items were on calculations of the surface area of shapes (cube, cuboids, cone, cylinder and sphere). IIS initially was a 25 items structured likert-type scale of Strongly Agree (SA), Agree (A), Disagree (D) and Strongly Disagree (SD). The inventory had questions such as calculations of surface areas of objects in mathematics makes the subject interesting; it would be exciting to participate in calculating the surface area of a solid shape and students who dodge classes of finding the surface of a solid should not be blame.The two instruments were subjected to face and content validation by three expert in mathematics education and three in psychology. Their comments, suggestions and corrections were adhered to, which resulted to the reduction of MPT to 25 items and IIS to 20 items. The two instruments were trial tested on 30 students who were not part of the study but had homogenous qualities as those in the study. The data collected from the trial test were used to ascertain the reliability of the instruments. The Richard Kuderson Formula 20 and 21 were used to calculate the reliability of IIS and MPT, and reliabilities of 0.75 and 0.81 were obtained respectively.

The regular teachers of the two schools were used as research assistance. A training programme was organized for the teacher who took the experimental group. He was exposed to the steps for using ICT as the resource for teaching the topic surface area of solid shapes. The teacher of the control group was left to use the conventional approach. All necessary material using ICT for each of the students were made available. The MPT and IIS were administered and collected back before the lesson commence for both groups. The experimental group was taught using ICT as learning objects in which packages for teaching surface area were installed. The students were first made to bring up the different solids whose surface areas were to be found in 
different forms. On the second stage, they were made to appreciate how the different surfaces of each of the solids are pulled apart and reassembled to form the solid shape. This makes the students identify and recognized the different surfaces that make each of the solids. The pulling apart and reassembling is used to arouse the students' emotional interest.The students are then guided to link each of the 2-dimensional shapes pulled out from the solid shapes to the different formulas of the 2-dimensional shapes already known. The formulas were then applied in calculating the surface areas. The students were later guided to add the different areas to arrive at the total surface area of the solid. This was done in order to arouse students' cognitive interest.

The students are led into understanding that finding the surface area of a given solid is to pull out the 2dimensional shapes that can be fitted to give the solid. Find the areas of these 2-dimensional shapes and add them. This was related to real life situation where the surface areas of building and bridges are calculated by engineers be construction. This is expected to around the personal interest of the students. The control group was taught the same topics using the conventional approach. The period lasted for three weeks of single periods of $40 \mathrm{mins}$ and double period of $80 \mathrm{mins}$. This period was the specified period by the scheme of work. The teacher administered the MPT and IIS as posttest and post-interest at the end of the study for both groups. The scripts well collected and scored by the teachers using the marking guide of the researcher. The MPT was scored 4 marks for any correct item while for IIS, Strongly Agree - 4, Agree - 3, Disagree - 2 and Strongly Disagree 1. For negative items the scores were reversed.

\section{Results}

The results of the study were presented based on the research questions and their corresponding hypotheses.

\subsubsection{Research Question One}

What is the difference between the performance of students taught using ICT as resource and those taught without.

This research question was answered using mean

Table 1: Summary of Mean and Standard Deviation of Pretest and Posttest Score of Students Taught with and Without ICT

\begin{tabular}{|l|l|l|l|l|l|l|}
\hline \multirow{2}{*}{ Group } & \multirow{2}{*}{ N } & Pretest & \multicolumn{2}{|l|}{ Posttest } & \multirow{2}{*}{ Mean Gain } \\
\cline { 3 - 6 } & & X & SD & X & SD & \\
\hline Experimental & 48 & 28.92 & 10.7 & 67.58 & 6.61 & 38.66 \\
Control & 57 & 28.63 & 9.5 & 60.07 & 5.15 & 31.44 \\
Total & 105 & 28.76 & 1.02 & 63.50 & 6.94 & 34.74 \\
\hline
\end{tabular}

As shown in Table 1, the mean gain of the experimental group is 38.66 while that of the control is 31.44. This implies that students taught using ICT as a resource performed better than those taught with the conventional method. In order to ascertain if this difference is significant, the data were further subjected to the Analysis of Covariance (ANCOVA) as shown in table 4.

\subsubsection{Research Question Two}

What is the difference between the interest of students taught with ICT and those taught without? This research question was answered using means.

Table 2: Summary of Mean and Standard Deviation of Pre-interest and Post-interest of Experimental and Control Groups Including Interest Mean Gain

\begin{tabular}{|l|l|l|l|l|l|l|}
\hline Group & \multirow{2}{*}{$\mathbf{N}$} & \multicolumn{2}{|l|}{ Pre-interest } & \multicolumn{2}{l|}{ Post-interest } & Interest \\
\cline { 3 - 6 } & & X & SD & X & SD & Gain \\
\hline Experimental & 48 & 37.85 & 7.38 & 63.08 & 9.63 & 25.23 \\
Control & 57 & 37.30 & 7.64 & 57.70 & 7.87 & 20.40 \\
Total & 105 & 37.55 & 7.49 & 60.16 & 9.09 & 22.61 \\
\hline
\end{tabular}

As shown in Table 2, the interest mean gain of the experimental group was 25.23 while that of the control group was 20.40. This implies that the experimental group had a greater interest mean gain than the control group. In order to ascertain whether this difference was significant, the data were further subjected to the Analysis of Covariance (ANCOVA) as shown in table 5.

\subsubsection{Research Question Three}

What difference exists between the performance of male and female students taught with ICT and those taught without? This research question was answered using mean 
Table 3: Summary of Mean and Standard Deviation of Pretest and Posttest Scores of Male and Female Students of the Experimental and Control Groups

\begin{tabular}{|l|l|l|l|l|l|l|}
\hline Group & \multirow{2}{*}{$\mathbf{N}$} & Pretest & Posttest & \multirow{2}{*}{ Mean Gain } \\
\cline { 3 - 6 } & & $\mathbf{X}$ & SD & X & SD & \\
\hline Male & 64 & 28.19 & 9.73 & 63.81 & 7.18 & 35.62 \\
Female & 41 & 29.66 & 10.51 & 63.02 & 6.62 & 33.36 \\
Total & 105 & 28.76 & 10.02 & 63.50 & 6.94 & 34.74 \\
\hline
\end{tabular}

Table 3 revealed that the mean gain of male students was 35.62 while that of female was 33.36 . This indicates that male students performed better than female students. In order to ascertain whether this difference was significant, the data were further subjected to the Analysis of Covariance (ANCOVA) as shown in table 6.

\section{$1.8 \quad$ Hypotheses Testing}

The hypotheses were tested using the Analysis of Covariance (ANCOVA).

\subsubsection{Hypothesis One}

There is no significant difference between the performance of students taught with ICT as a resource and those taught without.

Table 4: Covariance Analysis of Pretest and Posttest Scores of Students Taught with ICT and Those Taught without.

\begin{tabular}{|l|l|l|l|l|l|}
\hline Source & Sum of squares & df & Mean square & F & Sign @ P<.05 \\
\hline Corrected Model & 1464.98 & 2 & 742.49 & 21.46 & .000 \\
Intercept & 44291.04 & 1 & 44291.04 & 1280.06 & .000 \\
Pretest & 14.12 & 1 & 14.12 & 0.41 & .524 \\
Group & 1466.46 & 1 & 1466.46 & 42.38 & .000 \\
Error & 3529.27 & 102 & 34.60 & & \\
Total & 428464.00 & 105 & & & \\
Corrected Total & 5014.25 & 104 & & & \\
\hline
\end{tabular}

Table 4 showed that the calculated Probability value (P-value) .000 for Group is less than the declared probability value (Alpha level) .05. Therefore, the null hypothesis one is rejected. This implies that there exists a significant difference between the performance of students taught using ICT as a resource and those taught without.

\subsubsection{Hypothesis Two}

There is no significant difference between the interest of students taught using ICT as a resource and those taught without.

Table 5: Covariance Analysis of Pre-interest and Post-interest Scores of Students Taught with ICT and those taught without

\begin{tabular}{|l|l|l|l|l|l|}
\hline Source & Sum of squares & df & Mean square & F & Sign @ P<.05 \\
\hline Corrected Model & 1031.35 & 2 & 515.68 & 6.96 & .001 \\
Intercept & 10816.23 & 1 & 10816.23 & 146.07 & .000 \\
Pre-interest & 276.70 & 1 & 276.70 & 3.74 & .056 \\
Group & 720.06 & 1 & 720.06 & 9.72 & .002 \\
Error & 7552.90 & 102 & 74.05 & & \\
Total & 388627.00 & 105 & & & \\
Corrected Total & 8584.25 & 104 & & & \\
\hline
\end{tabular}

Table 5 revealed that the calculated P-value .002 of Group is less than the alpha level .05 . Therefore, the null hypothesis two is rejected. This implies that there exists a significant difference between the interest of students taught using ICT as a resource and those taught without.

\subsubsection{Hypothesis Three}

There is no significant difference between the performance of male and female students taught using ICT as a resource and those taught without.

Table 6: Covariance Analysis Pretest and Posttest Scores of Male and Female Students Taught Using ICT as Resource and Those Taught Without

\begin{tabular}{|l|l|l|l|l|l|}
\hline Source & Sum of squares & df & Mean square & F & Sign @ P<.05 \\
\hline Corrected Model & 36.67 & 2 & 18.34 & 0.38 & .688 \\
Intercept & 425585.57 & 1 & 42558.57 & 872.72 & .000 \\
Pretest & 21.15 & 1 & 21.15 & 0.43 & .512 \\
Gender & 18.15 & 1 & 18.15 & 0.37 & .543 \\
Error & 4977.57 & 102 & 48.80 & & \\
Total & 428464.00 & 105 & & & \\
Corrected Total & 5014.25 & 104 & & & \\
\hline
\end{tabular}


As shown in Table 6 , the calculated P-value .543 of gender is greater than the alpha level .05 . Therefore, the null hypothesis three cannot be rejected. This implies that there is no significant difference between the performance of male and female students taught using ICT as a resource and those taught without ICT.

\section{Discussion}

The result obtained from research question one and hypothesis one showed that the experimental group performed significantly better than the control group. This could be attributed to the students' personal involvement in using the system to upload various solid shapes, and the formation of the solid shapes using the surfaces of 2-dimension planes. This is in line with Usman \& Eze (2010) who found that computer used as a tool significantly enhances students' achievement in mathematics.The result in research question two and hypothesis two showed that there existed significant difference in the interest of the experimental and that of the control group. This significant difference was in favour of the experimental group. This could be attributed to the students using ICT in recognizing the different surfaces that form different solids through detachment and formation of those solids. This could thereby result to students' interest being arouse and transited from emotional, to cognitive and then to personal one. This is in line with Sunday (2010), who stated that ICT is a good resource for arousing students' interest in physics thereby enhancing their performance.The result in research question three and hypothesis three showed that there was no significant difference in the performance of male and female students though the performances of male students were better. This indicated that both male and female students performances were enhance equally, disagreeing with the saying that mathematics is a masculine subject. This is in line with Sunday (2010), who opined that ICT enhances both male and female achievements.

\section{Conclusion}

The use of ICT is found to arouse students' interest and improve their performance as well as bridge the gap between male and female students performance. These approaches help students in such a way that students are able to appreciate the relationship between 3-dimensional objects and 2-dimensional shapes when finding the surface area of a solid shape.

\section{Recommendations}

The findings of the study result to the following recommendations. Mathematics teachers should be encouraged to use ICT as a resource for teaching surface area of solid shape so as to enhance students' interests and performances.Mathematics Association of Nigeria (MAN) and the Science Teachers Association of Nigeria (STAN) should organize seminars and conferences on the development of a package and how to use it on the ICT as a resource for the teaching of surface area of solid. The government should provide ICT resources for schools especially those without ICT resources as this would enhance the use of those resources to improve students' interest and performance in mathematics.

\section{References}

[1]. Adedibu, A. A. \& Olayiwola, M. A. (2006). Selecting and Managing Resources for Chemistry Teaching: What the Teacher Should Know. In U. Nzewi Resources for Science, Technology and Mathematics (STM) Education. Proceeding of the $47^{\text {th }}$ Annual Conference of STAN Ibadan: STAN, pp. $178-180$.

[2]. Akinsola, M. K. (2000). Enriching Science, Technology and Mathematics Education: Effect of Resource Utilization on Students' Achievement in Geometry. 41 ${ }^{\text {st }}$ Annual Conference Proceedings of STAN, 289-291.

[3]. Folayan, S. A. \& Ibrahim, A. G. (2000). Mathematics/English Language. The Way Forward in Advanced Technology. Proceeding of Annual Conference of MAN, 97 - 103.

[4]. Ifamuyiwa, A. S. (2007). Mathematics Education for Sustainable Development. In U. Nzewi Science, Technology and Mathematics (STM) Education for Sustainable Development. Proceeding of the 50 ${ }^{\text {th }}$ Annual Conference of STAN. $162-165$.

[5]. Ochoyi, U. E. \& Ukwumonu, A. T. (2008). Integration of ICT in Seocndary School Curriculum in Nigeria: Problem and Prospects. In N. Udofia, Curriculum Development in Science, Technology and Mathematics (STM) Education. Proceeding of the $49^{\text {th }}$ Annual Conference of STAN $207-211$.

[6]. Ochoiji, U. E. \& Danladi, P. (2009). Challenges for Mathematics Teachers in the Teaching of Measurement under the Universal Basic Education (UBE) Scheme in Nigeria. Journal of Mathematics Association of Nigeria, 34 (1), 85 - 90.

[7]. Okereke, S. C. (2006). Effect of Prior Knowledge of Implication of Mathematical Tasks/Concepts to Career Types and Gender on Students' Achievement, Interest and Retention. In U. Nzewi Resources for Science, Technology and Mathematics (STM) Education. Proceeding of the $47^{\text {th }}$ Annual Conference of STAN Ibadan: STAN, pp. $253-259$.

[8]. Okigbo, E. C. \& Okeke, S. O. C. (2011). Effect of Games and Analogies on Students' Interest in Mathematics. Journal of Science Teachers Association of Nigeria, 46 (1), $101-112$.

[9]. Sunday, A. A. (2010). Impact of Information and Communication Technology (ICT) on teaching and learning of Physics. International Journal of Educational Research and Technology 1(2), 48 -59.

[10]. Ting, T. L. (2010). Using Mainstream Game to teach technology through an interest framework. Educational Technology \& Society, $13(2), 141-152$.

[11]. Udousoro, U. J. (2006). Suitability of the Mathematics Teacher Education Programme as Viewed by Serving Mathematics Teachers. In U. Nzewi Resources for Science, Technology and Mathematics (STM) Education. Proceeding of the 47 ${ }^{\text {th }}$ Annual Conference of STAN Ibadan: STAN $242-246$

[12]. Umeh, M. O. (2006). Availability and Use of Human and Material Resources in the Teaching of Ecology and Genetics in Biology Education in Senior Secondary Schools in Anambra State. In U. Nzewi Resources for Science, Technology and Mathematics (STM) Education. Proceeding of the $47^{\text {th }}$ Annual Conference of STAN Ibadan: STAN, pp. $128-133$.

[13]. Usman, K. O. \& Ezeh, S. I. (2010). Computer as Tutor and Tool in Mathematics Instruction for the Attainment of Millennium Development Goal. Journal of Mathematical Sciences Education, 1 (1), 133 - 141. 